journal of architecture, Volume 9 I Nomor 2 I Agustus |

2020

\title{
BANJARMASIN FUTSAL CENTER
}

\author{
Kevin Christiansyah \\ Program Studi Teknik Arsitektur Fakultas Teknik Universitas Lambung Mangkurat \\ kevin.christiansyah1807@gmail.com \\ Muhammad Tharziansyah \\ Program Studi Teknik Arsitektur Fakultas Teknik Universitas Lambung Mangkurat \\ mtharzi@gmail.com
}

\begin{abstract}
ABSTRAK
Banjarmasin Futsal Center muncul sebagai jawaban atas beberapa permasalahan yang ada dalam dunia futsal di Banjarmasin. Permasalahan yang dimaksud adalah kurang memadainya fasilitas pada sebagian besar futsal center yang ada di Banjarmasin. Selain itu, citra bangunan dari futsal center tersebut juga turut menjadi masalah, yang mana kurang mencerminkan citranya sebagai suatu gedung olahraga, Metode arsitektur yang digunakan dalam menjawab permasalahan tersebut adalah metode architectural programming dengan merujuk kepada standarisasi ruang pada gedung olahraga yang meliputi ruang-ruang yang harus tersedia pada gedung olahraga beserta standar minimal ukuran ruang tersebut. Konsep representatif juga digunakan sebagai dukungan dalam memberikan gambaran mutlak tentang citra gedung olahraga kepada masyarakat. Gedung olahraga pada dasarnya tidak memiliki ciri-ciri khusus terkait citra bangunannya yang tercantum dalam sebuah teori, maka dari itu Banjarmasin Futsal Center dirancang dengan melakukan pendekatan kepada stadion sepakbola terutama dari segi bentuknya sehingga dapat dikenal sebagai "Mini Stadium".
\end{abstract}

Kata kunci: Futsal, Gedung Olahraga, Representatif

\begin{abstract}
Banjarmasin Futsal Center appears as an answer to some problems that exist in the world of futsal in Banjarmasin. The problem is the lack of effectiveness of facilities for most futsal center in Banjarmasin. In addition, the image building of futsal centers also contributed to the problem, which is less reflect its image as a sports hall. Architecture method used in answering the problems is architectural programming method by referring to the standardization of building space in sports hall that include spaces must available in the sports hall along with the minimum standards of the room size. Representative concept also used as a support in providing the absolute picture of sports hall's image to the public. Sports hall basically do not have special characteristics related to the image of the building contained in a theory, therefore Banjarmasin Futsal Center is designed by approaching the football stadium especially in terms of its shape so that it can be known as "Mini Stadium".
\end{abstract}

Keywords: Futsal, Sports Hall, Representation 


\section{LATAR BELAKANG}

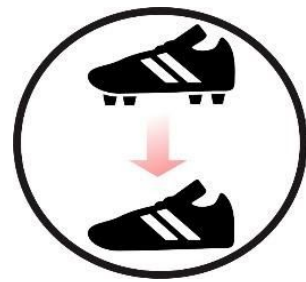

Futsal merupakan

olahraga hasil adaptasi dari sepakbola, yang mana dimainkan dengan teknik yang sama, hanya saja berbeda sedikit dari segi peraturan. Kebanyakan masyarakat hanya dapat merasakan bermain futsal dibandingkan sepakbola dikarenakan ketersediaan lapangannya, yang mana lapangan futsal terbilang tersedia lebih menjamur dikarenakan ukurannya yang lebih kecil dan dapat bersifat indoor sehingga lebih mudah diadakan.

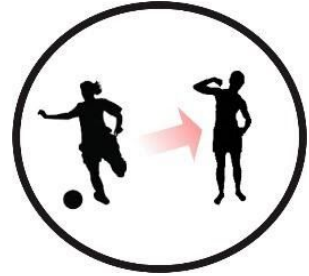

Seperti yang sudah diketahui dari segi teknik bermain, futsal hampir sama dengan sepakbola bahkan futsal terbilang lebih cepat dari segi tempo permainannya karena dimainkan dilapangan yang relatif kecil sehingga setiap pemain dituntut untuk melakukan banyak pergerakan diikuti dengan kecepatn. Pergerakan dan kecepatan tersebut tentunya membantu para pemain futsal membakar kalori dalam tubuhnya,maka dari itu futsal merupakan salah satu olahraga yang menyehatkan.

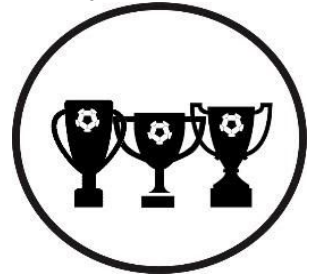

Seiring dengan meningkatnya popularitas futsal khususnya di Banjarmasin, beberapa instansi juga semakin giat untuk mengadakan kompetisi dalam berbagai skala baik itu skala anak-anak, remaja dewasa hingga mencakup semua umur. Beberapa nama besar seperti Pocari Sweat, Hydro Coco Jotun dll terbilang rutin mengadakan kompetisi tiap tahunnya. Kompetisi tersebut biasanya diadakan di wadah penyewaan gedung futsal yang ternilai cukup besar dan baik. Dengan sering diadakannya kompetisi, para pemain futsal dapat menumbuhkan jiwa berkompetisi, meningkatkan kepercayaan diri dan skill individu serta menyatukan diri ke dalam kelompok.

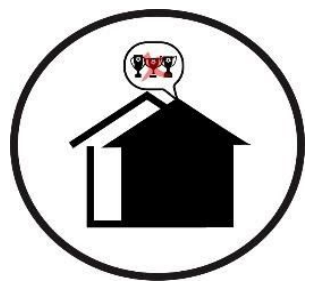

$\begin{array}{lrr}\begin{array}{l}\text { Sebagai lanjutan dari } \\ \text { segmen }\end{array} \text { sebelumnya, } \\ \text { Banjarmasin } & \text { terbilang } \\ \text { belum memiliki } & \text { futsal } \\ \text { center yang } & \text { dapat } \\ \text { mewadahi } & & \text { berbagai } \\ \text { kegiatan futsal } & \text { secara }\end{array}$ nyaman terutamanya untuk kompetisi yang terbilang besar. Tercatat ada 16 futsal center di Banjarmasin, akan tetapi dari keenam belas futsal center tersebut terbilang tidak efektif karena belum sepenuhnya memenuhi persyaratan sebuah gedung olahraga. Ketidakefektifan tersebut ditinjau dari segi fasilitas utama hingga pendukung aktivitas futsal.

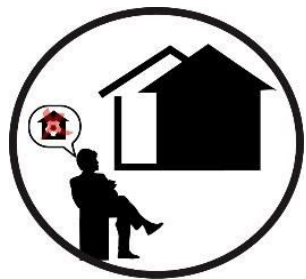

Selain daripada fasilitas futsal, permasalahan futsal center di Banjarmasin juga terletak pada tampilan bangunannya, yang mana dari keseluruhan futsal center yang ada di Banjarmasin masih terbilang belum ada yang dapat menggambarkan dirinya sebagai sebuah gedung olahraga, melainkan lebih terkesan sebagai bangunan dengan fungsi lainnya karena bentukan dan elemen yang terletak pada rancangannnya yang tidak direncanakan dengan baik dan hanya terfokus pada penyediaan sekedar wadah untuk futsal.

\section{PERMASALAHAN}

Inti dari keseluruhan latar belakang yang ada adalah Banjarmasin memerlukan satu wadah yang terbilang efektif untuk melingkupi aktivitas olahraga futsal dalam skala nasional. Namun, tidak sekedar menghadirkan sebuah wadah, melainkan wadah tersebut perlu dirancang dengan citra yang memiliki gambaran jelas sebagai gedung olahraga. Maka dari itu, permasalahan arsitektural yang muncul sebagai kesimpulan dari semuanya adalah "Bagaimana rancangan futsal center yang efektif dan representatif menggambarkan citra sebuah gedung olahraga?". 


\section{TINJAUAN PUSTAKA}

\section{A. Tinjauan Gedung Olahraga}

Gedung olahraga adalah bangunan yang mewadahi berbagai olahraga di dalam ruangan tertutup maupun terbuka. Fungsi utama gedung olahraga adalah sebagai wadah dalam melakukan kegiatan yang berhubungan dengan olahraga, yang mana kegiatan olahraga tersebut terdiri dari dua kategori, yaitu kompetitif dan rekreatif. Pertimbangan pertama yang dilakukan dalam melakukan perancangan gedung olahraga adalah menentukan jenis gedung olahraga berdasarkan sasaran jumlah penonton yang dapat ditampung seperti pada tabel berikut:

Tabel 1. Klasifikasi Gedung Olahraga

\begin{tabular}{|c|c|}
\hline $\begin{array}{c}\text { Klasifikasi } \\
\text { Gedung Olahraga }\end{array}$ & $\begin{array}{c}\text { Jumlah Penonton } \\
\text { (Jiwa) }\end{array}$ \\
\hline Tipe A & $3000-5000$ \\
\hline Tipe B & $\mathbf{1 0 0 0 - 3 0 0 0}$ \\
\hline Tipe C & Maksimal 1000 \\
\hline
\end{tabular}

Banjarmasin Futsal Center dirancang dengan mengikut kepada standar gedung olahraga tipe B dengan sasaran daya tampung pengunjung kisaran 1000-3000 orang. Pengunjung yang dapat ditampung di dalamnya tentu terlingkupi oleh beberapa ruang yang secara umum diperlukan oleh setiap jenis olahraga yang bersifat indoor. Berdasarkan Standar Nasional Indonesia (SNI), gedung olahraga tipe B meliputi ruang-ruang sebagai berikut:

- Ruang ganti atlet

- Ruang ganti pelatih dan wasit

- Ruang pijat

- Ruang P3K

- Ruang pemanasan

- Ruang latihan beban

- Toilet penonton

- Kantor pengelolaan

- Gudang

- Ruang panel

- Ruang mesin
- Kantin

- Pos keamanan

- Ticket Box

- Ruang pers

- Ruang VIP

- Parkir

- Toilet penyandang cacat

Selain daripada ruang-ruang tersebut, Banjarmasin Futsal Center sebagai gedung olahraga yang dikhususkan bagi olahraga futsal memiliki satu ruang utama, yaitu lapangan futsal. Perancangan lapangan futsal tersebut juga mengacu kepada standar yang sudah ditetapkan oleh Fifa, yakni standar ukuran. Keterangan jelas mengenai standar ukuran tersebut dapat kita lihat pada tabel di bawah ini:

Tabel 2. Tingkatan Ukuran Lapangan Futsal

\begin{tabular}{|c|c|c|}
\hline Tingkatan & Panjang & Lebar \\
\hline Regional & $25 \mathrm{~m}$ & $15 \mathrm{~m}$ \\
\hline Nasional & $\mathbf{2 5 - 4 2} \mathbf{~ m}$ & $\mathbf{1 5 - 2 5} \mathbf{~ m}$ \\
\hline Internasional & $25-42 \mathrm{~m}$ & $18-42 \mathrm{~m}$ \\
\hline
\end{tabular}

Lapangan futsal yang dipilih untuk mengisi Banjarmasin Futsal Center adalah lapangan berstandar nasional dengan ukuran panjang 42 meter dan lebar 25 meter. Material lantai yang digunakan adalah interlock. Material tersebut menyesuaikan dengan standar yang seringkali dipakai untuk lapangan berstandar nasional hingga internasional.

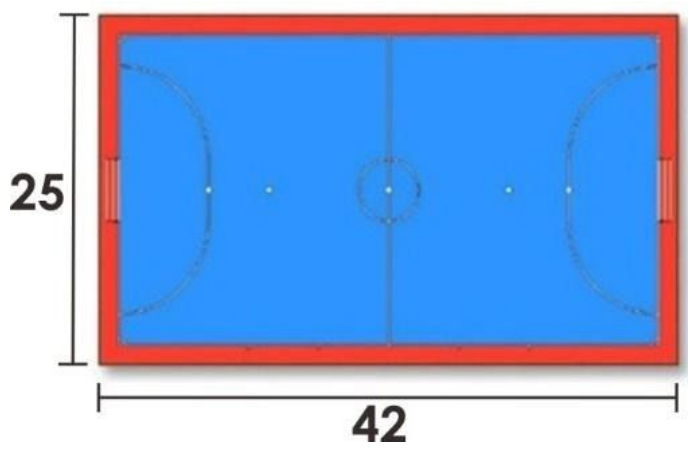

Gambar 1. Lapangan Futsal Standar Nasional 


\section{B. Tinjauan Konsep Representatif Gedung Olahraga}

Secara umum kata representatif memiliki pengertian sebagai "dapat (cakap, tepat) mewakili; sesuai dengan fungsinya sebagai wakil". Pengertian tersebut juga berlaku di dalam dunia arsitektur, yang mana mengarah kepada sebuah konsep dalam perancangan arsitektur. Konsep yang dimaksud berupa simbol-simbol dengan arti mendalam dari suatu objek yang diterapkan ke dalam pembentukan elemen suatu bangunan sehingga rancangan bangunan yang dihasilkan memiliki citra yang dapat memberikan gambaran mengenai jenis dan fungsi bangunannya.

Pada dasarnya tiap-tiap bangunan memiliki nilai representatif yang berbeda-beda sesuai dengan fungsinya. Akan tetapi, gedung olahraga terbilang tidak memiliki ciri khas terkait citra bangunan yang tercantumkan dalam satu teori, melainkan hanya ada standar terkait ruang beserta besarannya. Maka dari itu, penulis melakukan analisis terhadap beberapa studi kasus terkait ciri khas gedung olahraga, yang mana didapat seperti pada paparan berikut:

a. Gubahan massa yang unik

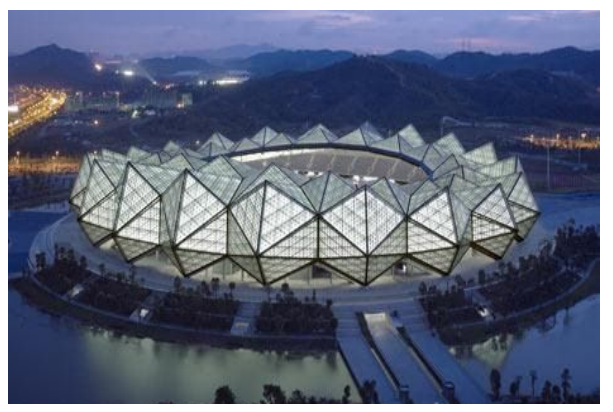

Gambar 2. Universiade Sport Center

Gubahan massa gedung olahraga yang memiliki nilai representatif cenderung dirancang dengan menjauhi bentukan kotak yang terbilang sudah terlalu umum. Pada dasarnya bentuk kotak memiliki keunggulan dari segi efektifitas ruang, namun memiliki kesan yang monoton sehingga lebih cenderung merepresentasikan bangunan dengan fungsi lainnya apabila tidak didukung oleh fasade yang memberikan gambaran secara langsung tentang olahraga. Bentuk kotak dapat terlihat lebih menarik apabila dipadukan dengan bentuk dasar lainnya terutamanya yang agak melengkung agar dapat memberikan kesan baru yang lebih menarik dan lebih dinamis serta modern.

b. Ekspos Struktur (Struktur Sebagai Elemen Estetika)

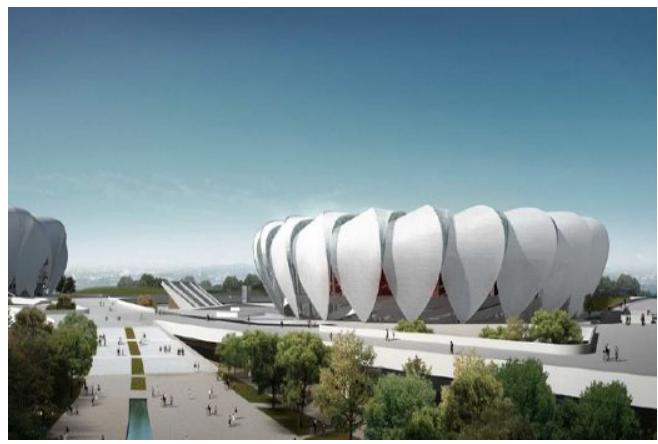

Gambar 3. Hangzhou Sport Center

Gedung olahraga selalu identik dengan bangunan bentang lebar, yang mana harus melingkupi beberapa ruang terkait aktivitas olahraga dengan salah satu ruangnya memiliki ukuran yang sangat besar dan harus terbebas dari kolom, yang tidak lain adalah arena olahraga. Struktur tentunya menjadi elemen paling penting dalam membentuk suatu gedung olahraga. Di balik struktur tersebut, citra bangunan yang terbentuk pun harus dapat merepresentasikan dirinya sebagai gedung olahraga. Oleh karenanya, kebanyakan gedung olahraga dirancang dengan menjadikan strukturnya sebagai bagian yang paling menonjol dan menarik dari keseluruhan citra bangunan, yang mana dalam dunia arsitektur hal tersebut biasa dikenal dengan istilah struktur sebagai elemen estetika. Rancangan gedung olahraga dibuat terkesan kokoh dengan struktur sebagai penopang utama berdirinya bangunan sekaligus pelengkap fasade yang terlihat mendominasi pada bagian eksterior 
bangunan. Struktur yang dimaksud biasanya adalah kolom, balok, dan atap.

c. Struktur dan Fasade Didominasi Material Baja dan Kaca

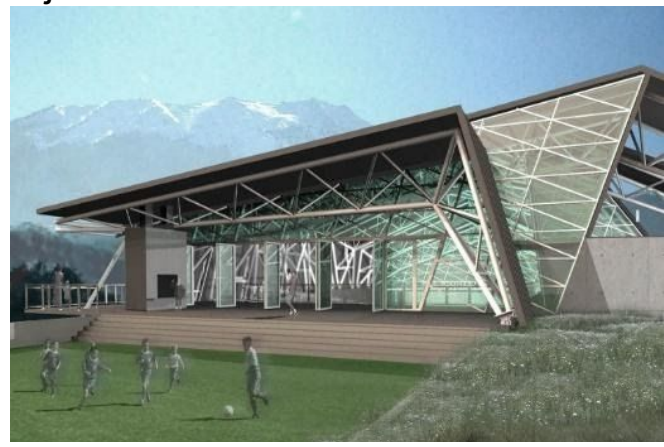

Gambar 4. Medeu Sport Center

Oleh karena struktur menjadi elemen paling penting bagi gedung olahraga maka material penyusun struktur tersebut pun menjadi hal penting berikutnya yang perlu dipertimbangkan dan diterapkan ke dalam rancangan. Material yang digunakan sebagai struktur utama gedung olahraga pada umumnya adalah baja, yang mana material ini memiliki kesan kokoh dan dapat difabrikasi menjadi berbagai bentuk menyesuaikan keinginan sehingga memiliki nilai lebih dari segi tampilan,. Selain itu, kestabilan dalam menerima beban menjadikan material ini semakin tepat untuk diaplikasikan ke dalam struktur gedung olahraga terutamanya pada kolom, balok, dan atap. Material baja juga dapat mengisi bagian fasad bangunan yang sudah dijabarkan pada segmen sebelumnya, yang mana struktur gedung olahraga juga sekaligus menjadi fasade bangunan. Fasad gedung olahraga juga turut diisi oleh material kaca yang memberikan kesan terbuka untuk optimalisasi cahaya yang masuk ke ruang sekaligus mengundang orang untuk datang karena memberikan kesan terbuka.

d. Penggambaran Ciri Khas Olahraga Pada Fasade

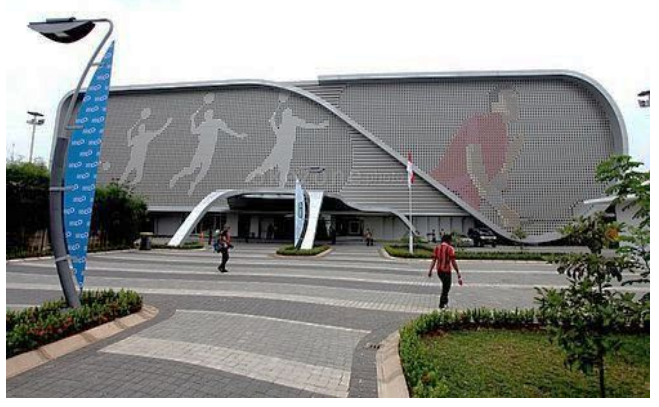

Gambar 5. Taufik Hidayat Arena

Guna memberikan nilai representatif yang lebih mendalam tentang citra bangunan gedung olahraga maka dapat dilakukan penggambaran secara langsung mengenai ciri khas suatu olahraga ke dalam rancangan bangunan yang menjadi point of view bagi pengamat. Gambaran tersebut biasanya diterapkan ke dalam bentuk detail arsitektural yang melekat pada fasad gedung olahraga. Untuk menyempurnakan gambaran tersebut tentunya diperlukan pemilihan yang tepat terhadap warna, material beserta komponen penyusun lainnya agar hasil pengaplikasiannya menjadi sangat menarik dan benar-benar tergambarkan .

\section{KONSEP DESAIN}

\section{A. Konsep Bentuk}

Sebelumnya sudah dijelaskan bahwa futsal merupakan olahraga hasil adaptasi dari sepakbola. Hanya saja wadah yang melingkupi kedua olahraga tersebut bisa terbilang sangat berbeda dari segi bentuknya. Stadion sepakbola tentunya memiliki nilai representatif yang lebih baik dibanding futsal center. Maka dari itu, bentuk bangunan yang akan dirancang coba diambil dari pendekatan terhadap bentuk stadion sepakbola. 

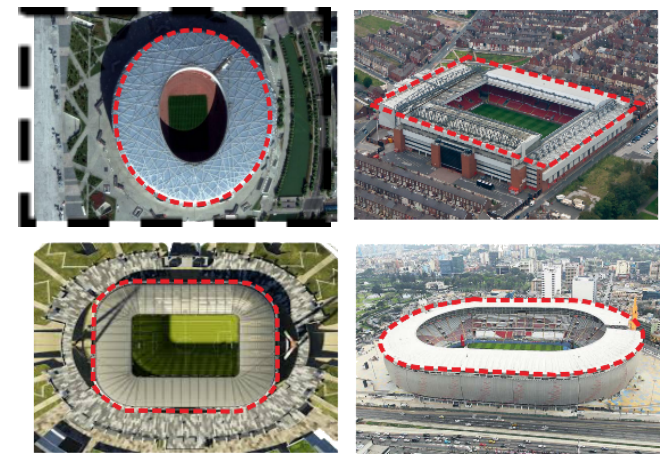

Gambar 6. Bentuk Dasar Beberapa Stadion Sepakbola

Bentuk oval tersebut tentunya tidak hanya seakan-akan dilakukan push ke atas, melainkan juga dilakukan beberapa transformasi guna semakin memberikan kesan menarik pada rancangan. Bagian depan bangunan hingga ke bagian depan belakang bangunan dibuat dengan ketinggian berbeda dalam artian semakin ke belakang semakin tinggi. Maksud dari transformasi tersebut adalah memberikan kesan seakan akan menyambut pengunjung. Di sisi lain juga mengikut kepada perletakan tribun dengan leveling yang banyak pada bagian belakang bangunan. Untuk lebih jelasnya terkait transformasi tersebut dapat kita pada gambar berikut:

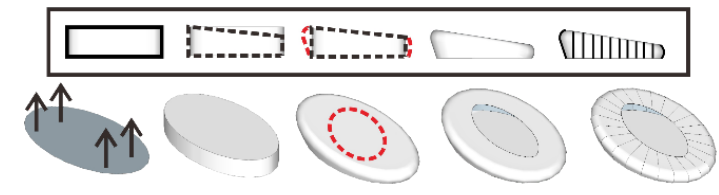

Gambar 7. Transformasi Bentuk Bangunan

Setelah didapat bentuk bangunan secara menyeluruh, arah hadap bangunan juga ditekankan pada rancangan Banjarmasin Futsal Center guna memaksimalkan keunikan bentuk yang telah dirancang. Arah hadap bangunan dengan bagian depan bangunan yang menghadap lurus mengikuti bentuk site terkesan kurang menarik sehingga diperlukan rotasi agar semakin mencuri pandangan pengamat. Rotasi yang dilakukan mengarah kepada semakin mencuri pandangan pengamat. Rotasi yang dilakukan mengarah kepada tingkat kemiringan jalan agar menjadi salah satu titik berat sebagai bangunan berciri khas di wilayah sekitar dan memberikan dampak bentuk yang unik kepada rancangan landscape.

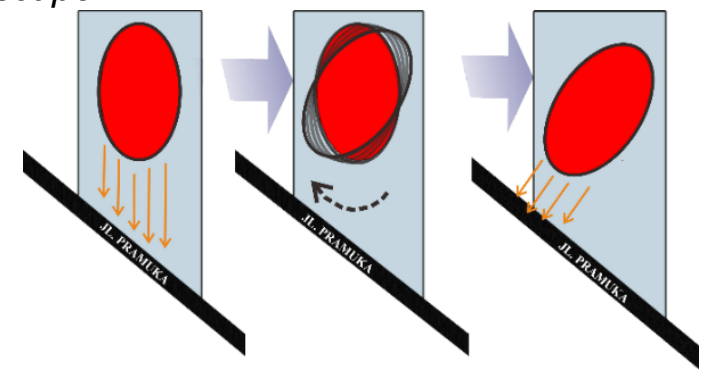

Gambar 8. Transformasi Bentuk Bangunan

\section{B. Konsep Ruang}

Banjarmasin Futsal Center terdiri dari 2 lantai, yang mana lantai 1 meliputi ruang-ruang yang bersifat tertutup dalam artian terlingkup penuh oleh dinding dan lantai 2 dikhususkan untuk ruang terbuka, yaitu tribun penonton. Tujuan daripada penempatan tribun pada lantai 2 tersebut agar ruang kosong yang dihasilkan dari bawah tribun dapat digunakan untuk keperluan ruang lainnya sehingga terkesan efektif. Untuk lebih lanjutnya mengenai susunan ruang dalam pada rancangan Banjarmasin Futsal Center, dapat kita lihat pada gambar berikut:
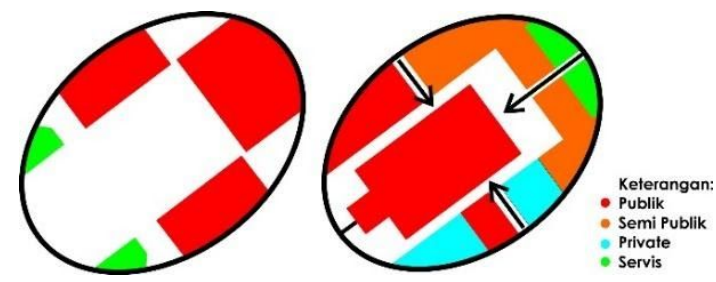

Gambar 9. Transformasi Bentuk Bangunan

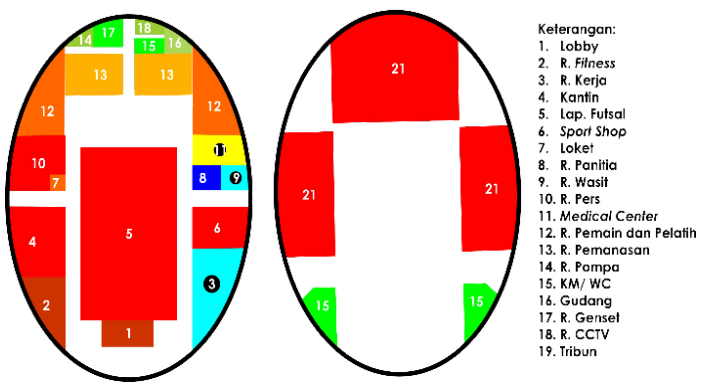

Gambar 10. Transformasi Bentuk Bangunan 


\section{HASIL RANCANGAN}

\section{A. Site Plan}

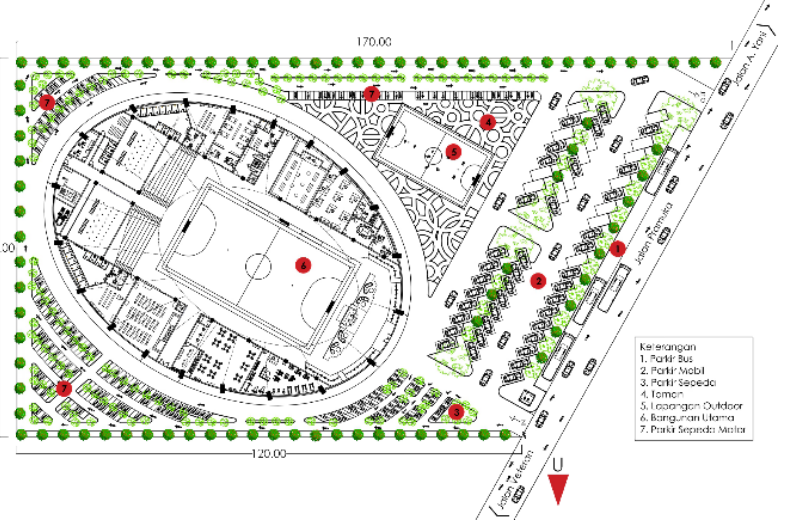

Gambar 11. Site Plan

\section{B. Denah}

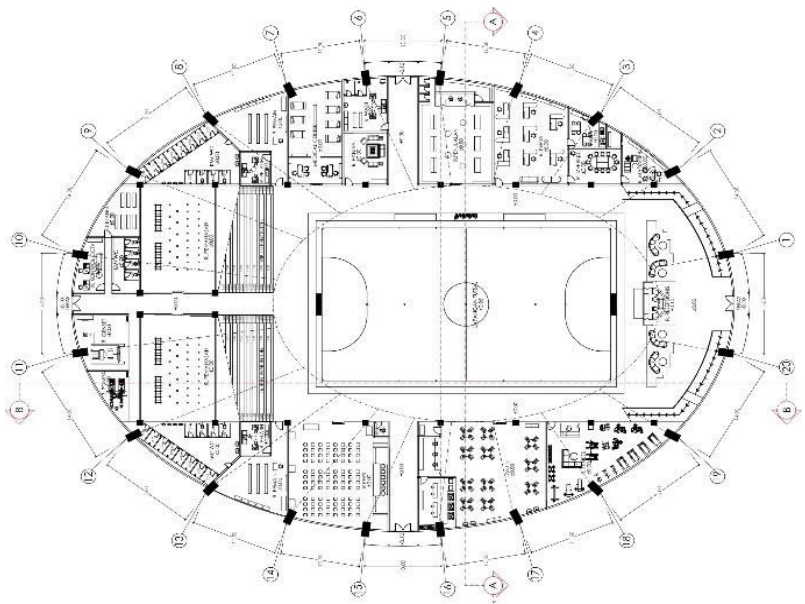

Gambar 12. Denah Lantai 1

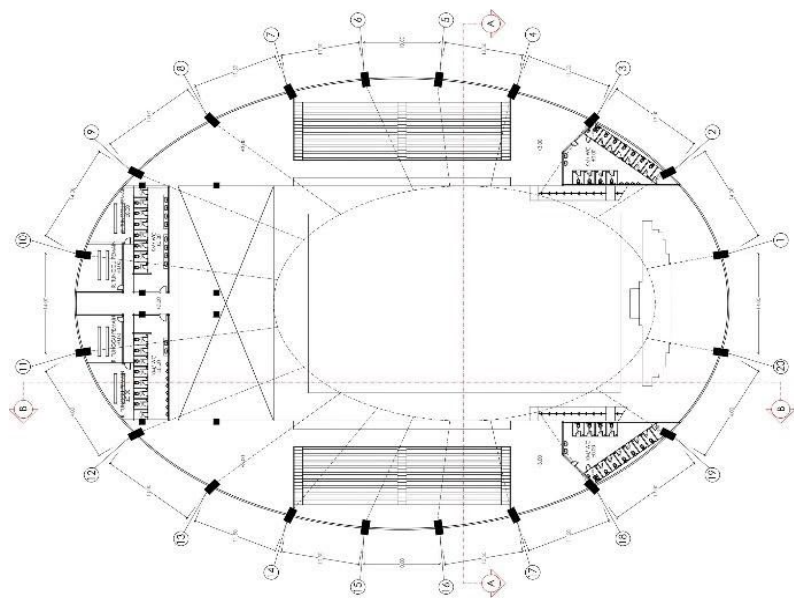

Gambar 13. Denah Lantai 2

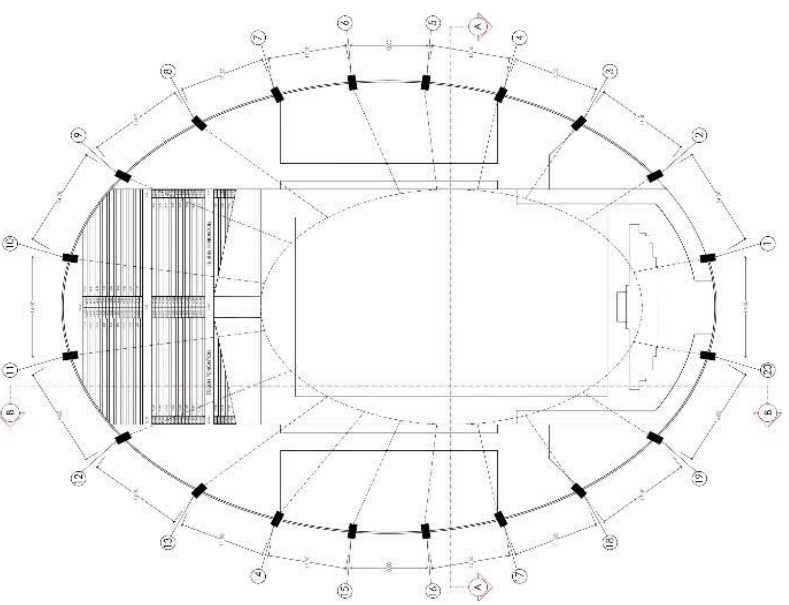

Gambar 14. Denah Lantai 3

C. Tampak Bangunan

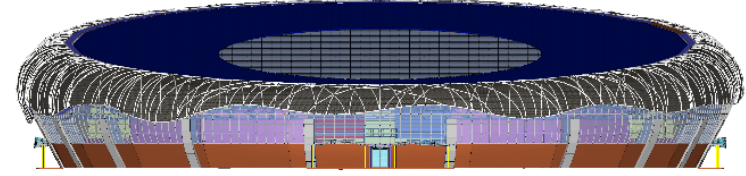

Gambar 15. Tampak Depan

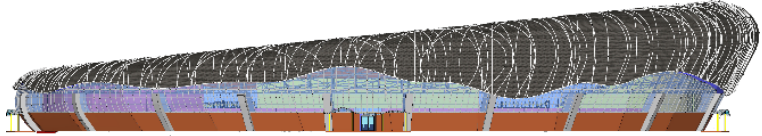

Gambar 16. Tampak Samping Kanan

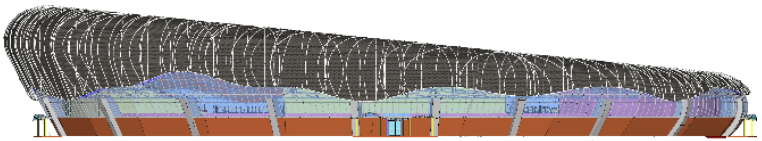

Gambar 17. Tampak Samping Kiri

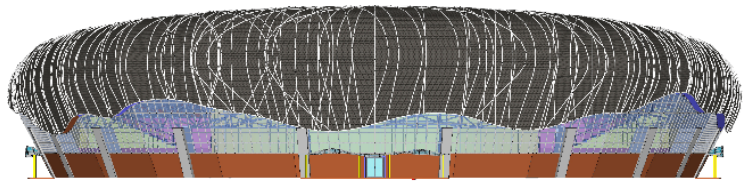

Gambar 18. Denah Lantai 2

D. Potongan Bangunan 


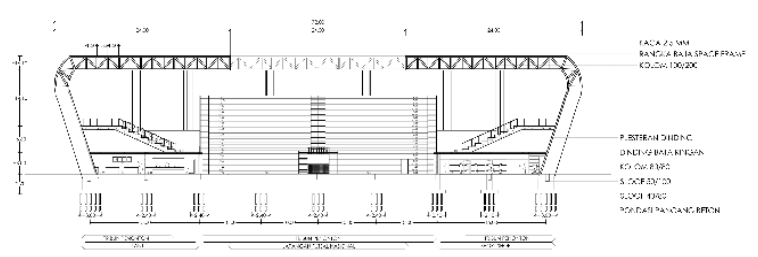

Gambar 19. Potongan A-A

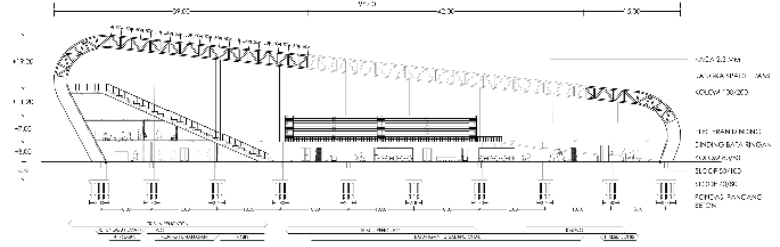

Gambar 20. Potongan B-B

\section{E. Interior Bangunan}

Lapangan futsal dan tribun di sekelilingnya menjadi ruang utama yang paling sering dipenuhi oleh pengunjung. Maka dari itu, interior lapangan beserta tribunnya dirancang dengan tereksposnya rangka atap space frame yang terbilang solid dan rapi diikuti dengan warna dinding yang tidak terlalu cerah dan warna tribun yang terdiri dari dua warna berbeda guna membedakan tribun untuk satu tim dengan tim lawannya.

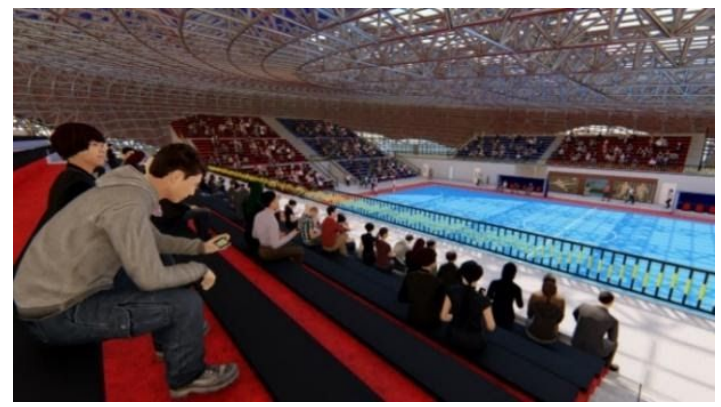

Gambar 21. Perspektif Interior Lapangan Futsal 1

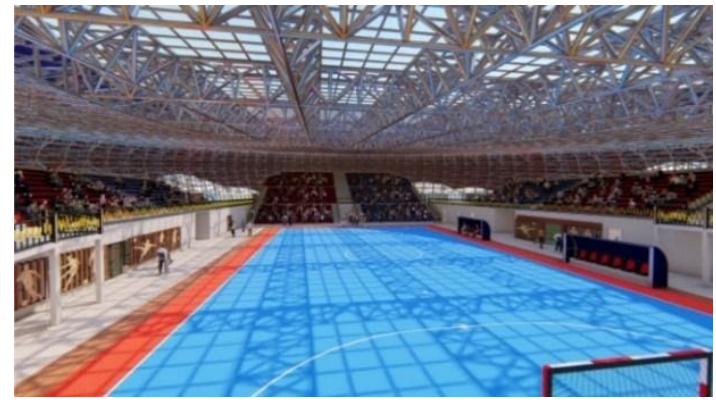

Gambar 22. Perspektif Interior Lapangan Futsal 2

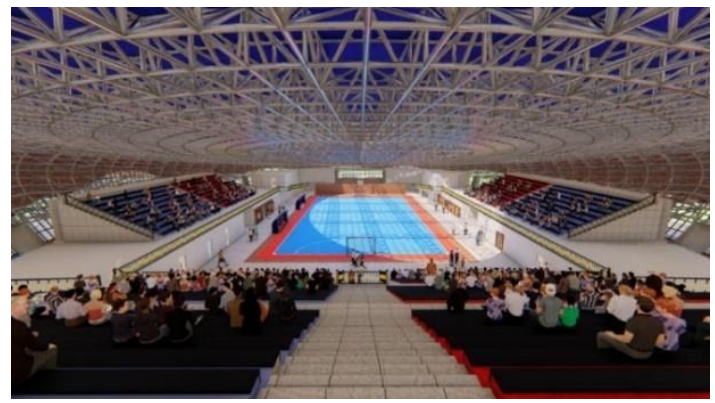

Gambar 23. Perspektif Interior Lapangan Futsal 3

Sama halnya dengan ruang-ruang lainnya, warna yang dipilih juga warna yang tidak terlalu cerah agar terkesan berkesinambungan dengan interior lapangan tersebut hanya saja rangka-rangka struktur ditutup menggunakan plafon karena jika tidak ditutup yang terekspos adalah struktur balok yang terkesan kurang menarik.

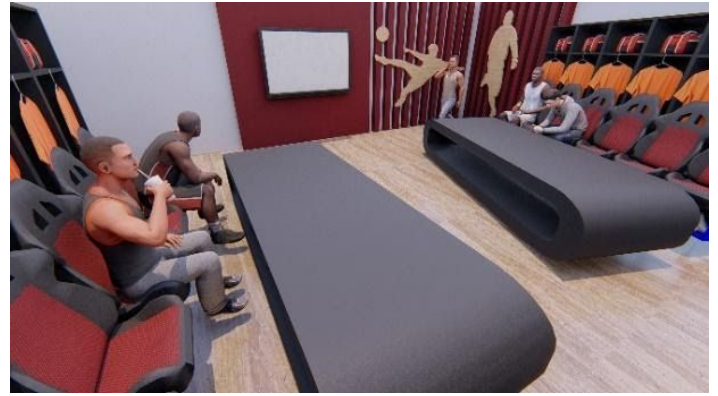

Gambar 24. Perspektif Interior Ruang Pemain 


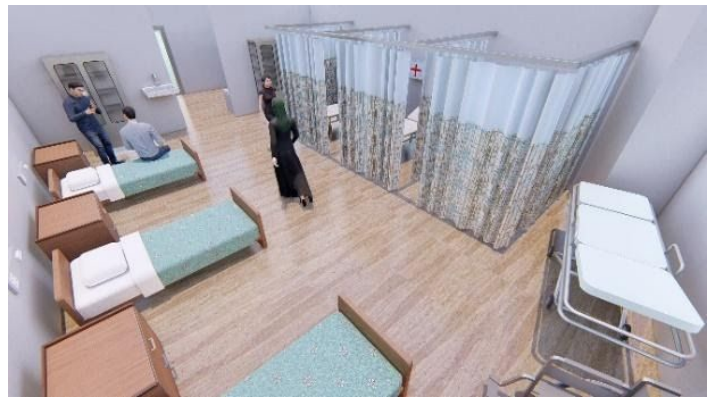

Gambar 25. Perspektif Interior Medical Center

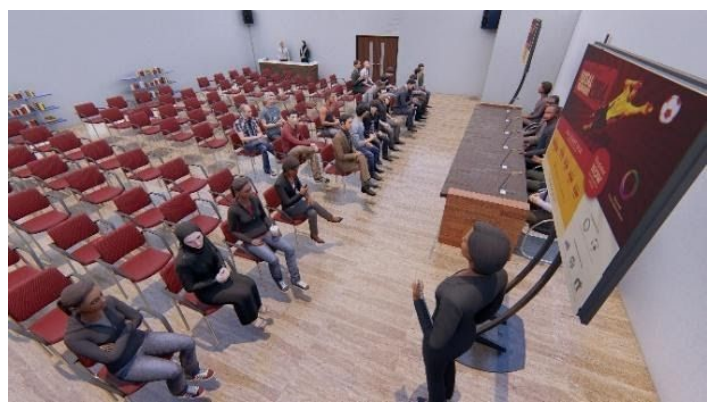

Gambar 26. Perspektif Interior Ruang Pers

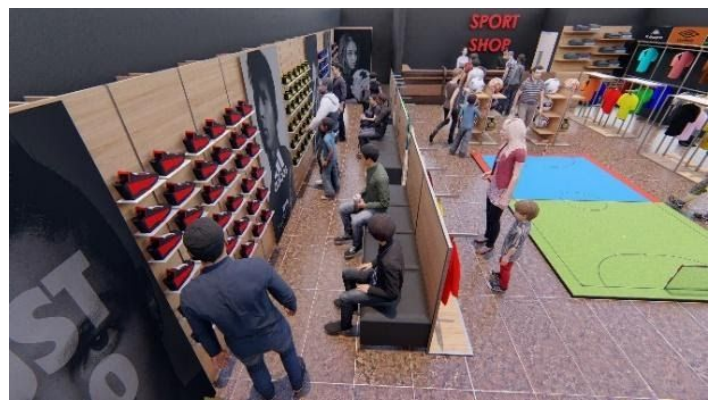

Gambar 27. Perspektif Interior Sport Shop

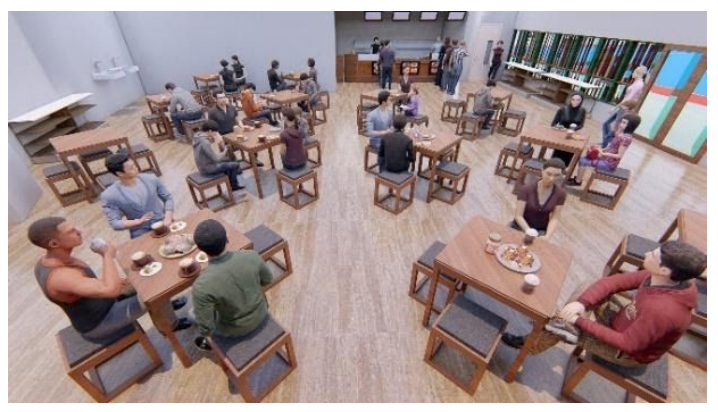

Gambar 28. Perspektif Interior Kantin

\section{F. Eksterior Bangunan}

Eksterior bangunan Banjarmasin Futsal Center menyerupai stadion sepakbola, hanya saja ada perbedaan yang mendasar diantaranya, yaitu pada bagian atas bangunan. Stadion sepakbola tentunya memiliki bagian atas atau atap yang terbuka karena sudah menjadi ciri khas sepakbola yang dapat terbilang sebagai olahraga outdoor, sedangkan futsal merupakan olahraga indoor yang pada umumnya dimainkan di lapangan tertutup sehingga pada atap rancangan Banjarmasin Futsal Center ditutup menggunakan material kaca agar air hujan tidak masuk dan cahaya alami dapat masuk secara maksimal sehingga tetap terasa kesan seperti stadion sepakbola.

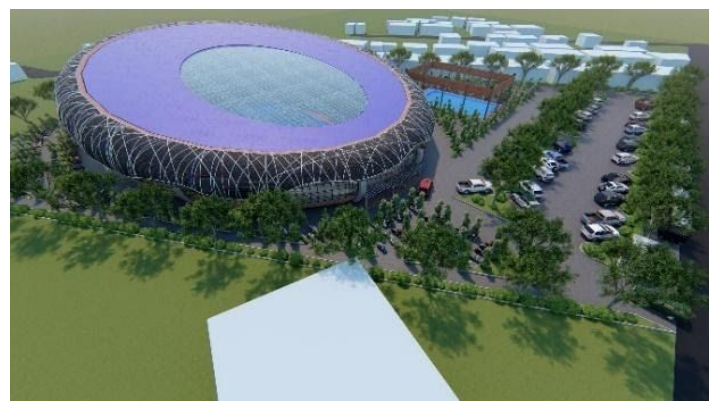

Gambar 29. Perspektif Eksterior 1

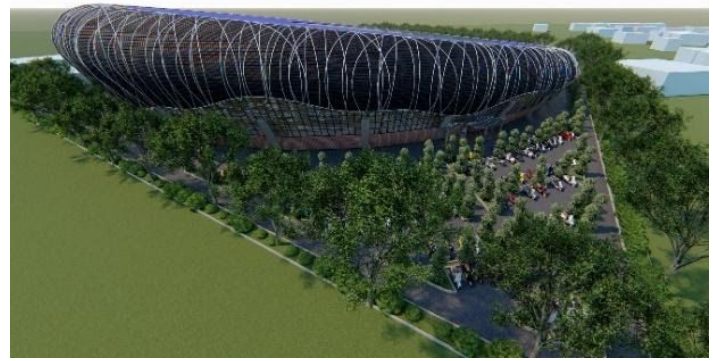

Gambar 30. Perspektif Eksterior 2

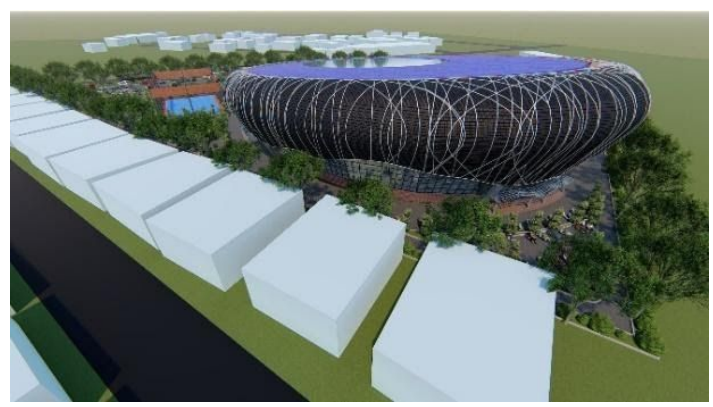

Gambar 31. Perspektif Eksterior 3 


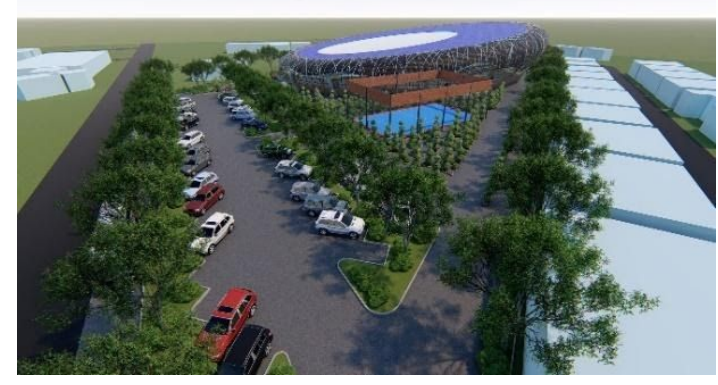

Gambar 32. Perspektif Eksterior 4

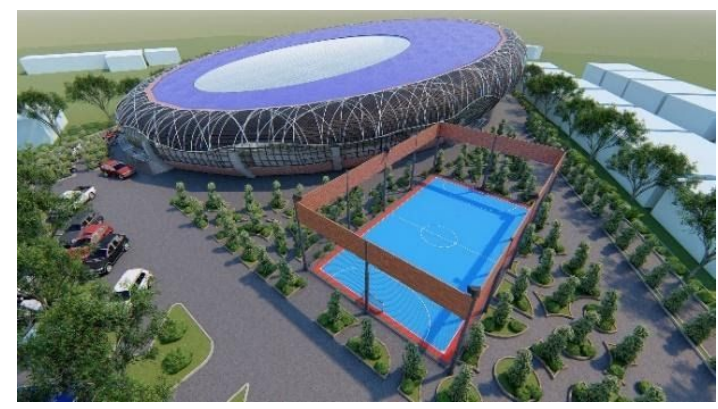

Gambar 33. Perspektif Eksterior 5

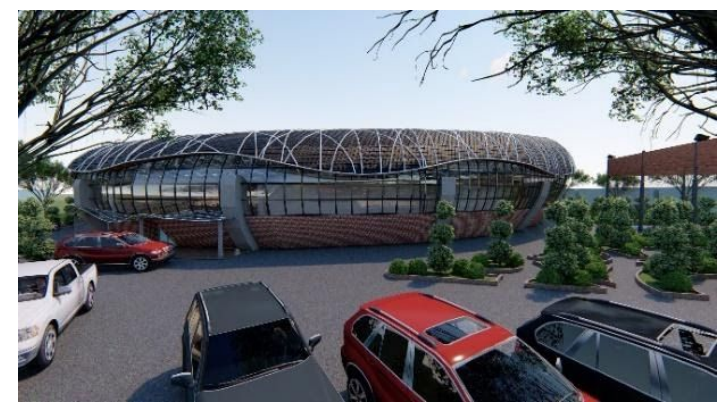

Gambar 34. Perspektif Eksterior 6

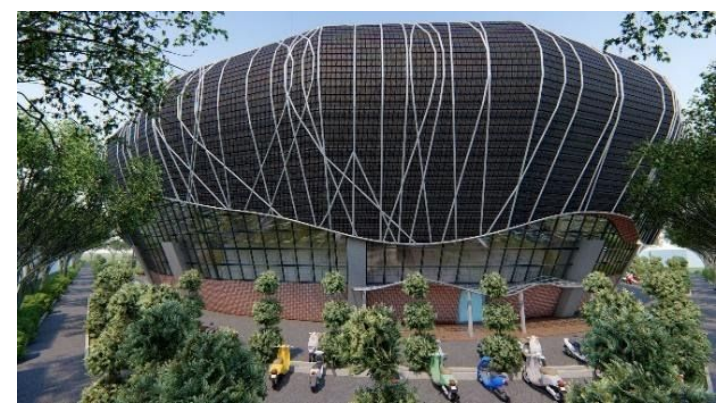

Gambar 35. Perspektif Eksterior 7

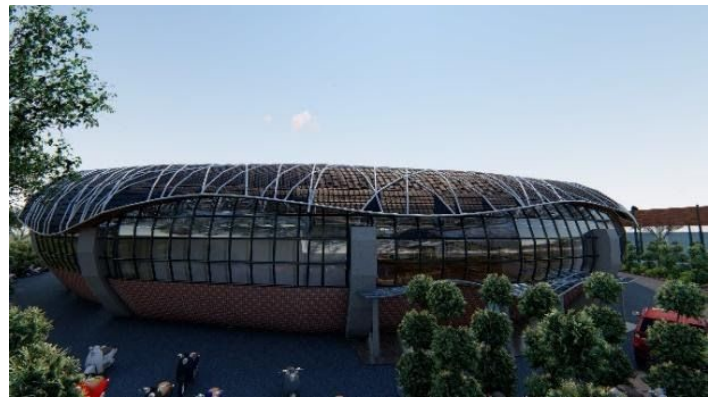

Gambar 36. Perspektif Eksterior 8

\section{KESIMPULAN}

Futsal merupakan salah satu olahraga favorit khususnya di Banjarmasin baik itu dari kalangan muda hingga kalangan dewasa. Hanya saja belum ada wadah yang terbilang cukup baik untuk mewadahi aktivitas futsal di Banjarmasin khususnya untuk kompetisikompetisi besar. Maka dari itu, Banjarmasin Futsal Center hadir sebagai jawabannya, yang mana dirancang dengan menghadirkan lapangan futsal berstandar nasional yang mengacu kepada standar Fifa. Selain itu, rancangan futsal center satu ini juga didukung oleh ketersediaan berbagai ruang beserta ukurannya yang mengacu kepada Standar Nasional Indonesia.

Citra bangunan tentunya juga menjadi fokus pada perancangan Banjarmasin Futsal Center, yang mana kebanyakan futsal center yang ada di Banjarmasin terbilang belum berhasil merepresentasikan dirinya sebagai suatu gedung olahraga. Pada dasarnya futsal center tidak memiliki ciri khas yang tercantum dalam suatu teori sehingga cukup sulit untuk memberikan nilai representatif tentang gambaran futsal center kepada masyarakat. Oleh karena olahraga yang sangat dekat dengan futsal adalah sepakbola, dan oleh karena wadah yang melingkupi sepakbola memiliki ciri khas yang kuat, maka perancangan Banjarmasin Futsal Center mengarah kepada stadion sepakbola terutamanya dari segi bentuk. Banjarmasin Futsal Center dapat dikatakan sebagai "Mini Stadium" yang mewadahi segala aktivitas yang berkatan dengan olahraga futsal. 


\section{DAFTAR PUSTAKA}

Departemen Pekerjaan Umum. (1994). Klasifikasi Gedung Olahraga. Tata Cara Perencanaan Teknik Bangunan Gedung Olahraga, 4-17. Dipetik 7 5, 2019, dari https://docplayer.info/30436655-Standar-s ni.html

Kurniati, F. (2015).Representatif. Representatif Sebagai Bentuk Komunikasi Dalam Arsitektur, 2-3. Retrieved 7 12, 2019, from https://temuilmiah.iplbi.or.id/wp-content/up loads/2015/11/TI2015-E-187-190Represe ntasi-sebagai-Bentuk-Komunikasi-dalamArsitektur.pdf

Marhaendro , A. S. (2004, 12). Lapangan . Dari Futsal Menuju Sepakbola, 92-96. Dipetik $7 \quad 1, \quad 2019, \quad$ dari http://staffnew.uny.ac.id/upload/13229585 0/penelitian/Dari+Futsal+Menuju+Sepakb ola.pdf

Riadi, M. (2018, 6 27). Lapangan, Peraturan dan Teknik Bermain Futsal. Retrieved 61 , 2019, from kajianpustaka.com: https://www.kajianpustaka.com/2018/06/la pangan-peraturan-dan-teknik-bermain-futs al.html

Saiful , A. (2018, 5 10). Standarisasi Gedung Olahraga. Dipetik 7 5, 2019, dari saiful0909.blogspot.com: https://saiful0909.blogspot.com/2018/05/st andarisasi-gedung-olahraga.html 